\title{
Intrauterine Route of Administration
}

National Cancer Institute

\section{Source}

National Cancer Institute. Intrauterine Route of Administration. NCI Thesaurus. Code C38272.

The administration of a drug within the uterus. 